\title{
EFEITOS DO PROGRAMA BOLSA FAMÍLIA SOBRE OS GASTOS DAS FAMÍLIAS BENEFICIÁRIAS EM MAURITI, CEARÁ
} EFFECTS OF THE BOLSA FAMIILIA PROGRAM ON THE EXPENSES OF BENEFICIARY FAMILIES IN MAURITI, CEARÁ

\section{Maria Aumeliana Pereira Sampaio}

Economista e Especialista em Administração Financeira pela Universidade Regional do Cariri (URCA).

\section{Eliane Pinheiro de Sousa}

Doutora em Economia Aplicada pela Universidade Federal de Viçosa (UFV), Pós-Doutoranda em Economia Aplicada pela Universidade de São Paulo (ESALQ/USP) e Professora Adjunta da Universidade Regional do Cariri (URCA).
Data de recebimento: $23-06-2013$ Data de aceite: 05-11-2014

\section{RESUMO}

O Programa Bolsa Família (PBF) representa a unificação dos doze programas já existentes e tem como objetivo principal combater a miséria e a fome no Brasil, propiciando o atendimento a famílias em situação de pobreza e extrema pobreza e, por consequência, possibilitando melhor bem-estar social a essas famílias. Assim, este estudo avalia os efeitos do PBF sobre os gastos das famílias beneficiárias no município cearense de Mauriti. Para atender este objetivo, foram empregados os métodos de análise tabular e descritiva e o teste t de Student para dados pareados. Os resultados indicam que há diferenças significativas entre os tipos de gastos realizados pelos beneficiários antes e depois que receberam o benefício do PBF. Verifica-se também que as famílias beneficiárias gastam a renda principalmente com gêneros alimentícios, passando a diversificar a cesta básica e melhorando a alimentação.

Palavras-chave: Programa Bolsa Família; consumo alimentar; bem-estar social.

\section{ABSTRACT}

The Bolsa Família Program (PBF) represents the unification of the twelve existing programs and has as its main objective to combat poverty and hunger in Brazil, providing care to families in poverty and extreme poverty and therefore enabling better welfare for these families. In this context, this study evaluates the effects of PBF on expenditures of beneficiary households in the Ceará municipality of Mauriti. To meet this objective, we employed the methods of descriptive and chart analysis and the Student $t$ test for paired data. The results indicated that there are significant differences between the types of costs incurred by the beneficiaries before and after they received the benefit of PBF. It can also be observed that the beneficiary households spend the income mainly in foodstuffs, diversifying the basket of staples and improving nutrition.

Keywords: Bolsa Familia, food consumption, social welfare. 


\section{INTRODUÇÃO}

Os programas de transferência condicionada de renda são políticas sociais cada vez mais utilizadas para combater a pobreza em países em desenvolvimento. Esses programas visam dar assistência às famílias pobres em curto prazo como forma de reduzir a pobreza corrente. Paralelamente, tais programas também promovem o investimento no desenvolvimento do capital humano por meio de condicionalidades do recebimento do benefício, combatendo a pobreza no longo prazo (RESENDE; OLIVEIRA, 2008).

De acordo com Baptistella (2012), o Programa Bolsa Família (PBF) representa o principal programa de transferência condicionada de renda, sendo responsável por grande parcela do orçamento social do Governo Federal e visto como um dos meios essenciais para a redução das disparidades existentes no Brasil, já que beneficia as famílias pobres e extremamente pobres com o intuito de combater a fome e propiciar segurança alimentar e nutricional para essas famílias beneficiárias. O destaque desse programa como principal política social do Governo Federal com o propósito de transferência direta de renda é corroborado por BRASIL (2012). Segundo essa referência, na região Nordeste, onde se localiza o município considerado neste estudo, a região receberá $R \$ 42,3$ bilhões do orçamento federal de 2013, repartido em seus nove estados e $R \$$ 14,2 bilhões não atribuídos a nenhum estado específico, mas para região Nordeste como um todo. Desse valor destinado à região Nordeste $(R \$ 14,2$ bilhões), parcela majoritária será destinada às áreas de Assistência Social (R\$ 11,2 bilhões), Gestão Ambiental ( $R \$ 1,6$ bilhão) e Saneamento ( $R \$ 904,5$ milhões), sendo que o recurso total remetido à assistência social será alocado integralmente para o pagamento do Programa Bolsa Família. Esse dado atesta a representatividade do programa.

O Programa Bolsa Família é a unificação desempenhada no ano de 2004 pelo ex- presidente
Luiz Inácio Lula da Silva, originado de doze programas organizados pela Rede de Proteção Social, que tinham como característica comum a transferência de renda para famílias e indivíduos. Os principais programas foram: Bolsa Escola, Bolsa Alimentação, Programa de Erradicação do Trabalho Infantil (PETI), Vale Gás e Cartão Alimentação.

O PBF foi criado sob regulamento da Lei Federal $n^{\circ} 10.836 / 04$ e está inserido em um dos eixos do Fome Zero', constituindo seu carro-chefe, mediante a transferência monetária mensal às famílias em condição de vulnerabilidade social, associado a uma rede de serviços públicos, interligada as políticas de Saúde, Educação e Assistência Social. O PBF tem como objetivo garantir uma renda básica para as pessoas menos favorecidas, condicionado ao cumprimento de uma agenda de ações que tem o objetivo de romper o círculo de transmissão da pobreza entre gerações por meio da promoção da saúde e da educação, tendo como finalidade unificar os programas de transferência de renda vigentes desde julho de 2001. De acordo com Tavares (2010), atualmente o PBF destina cerca de $R \$ 12$ bilhões ao atendimento de mais de 11 milhões de famílias com base no Orçamento Geral da União de dezembro de 2008.

No município cearense de Mauriti, objeto de estudo deste trabalho, verifica-se, a partir de análise realizada por meio dos dados lançados pelo Ministério do Desenvolvimento e Combate a Fome (MDS, 2013), uma crescente evolução no número de beneficiários do PBF desde sua criação. No ano de 2004, a cidade contava com 4,3 mil famílias beneficiadas, passando para 8,5 mil famílias em 2013.

\footnotetext{
O Fome Zero é uma estratégia impulsionada pelo governo federal para assegurar o direito humano à alimentação adequada às pessoas com dificuldades de acesso aos alimentos. Tal estratégia se insere na promoção da segurança alimentar e nutricional buscando a inclusão social e a conquista da cidadania da população mais vulnerável à fome.
} 
Esse programa visa atender famílias que estão em situação de pobreza e extrema pobreza, formadas por gestantes, nutrizes, crianças entre 0 e 12 anos ou adolescentes até 15 anos. No início do programa era considerada extremamente pobre ou pobre a unidade familiar cuja renda per capita mensal fosse de até $R \$ 50,00$ e $R \$ 100,00$, respectivamente. Atualmente, esses limites passaram a ser $R \$ 70,00$ e $R \$ 140,00$, respectivamente. Em 2008, o programa passou a atender jovens de 16 a 17 anos residentes em domicílios já beneficiados, com uma transferência de $\mathrm{R} \$ 30,00$ (Bolsa Jovem). Dependendo do tipo de beneficio, as famílias precisam se comprometer às condicionalidades do programa nas áreas de Saúde e Educação (TAVARES, 2008; 2010).

As condicionalidades correspondem aos compromissos assumidos tanto pelas famílias beneficiárias do Programa Bolsa Família, quanto pelo poder público para ampliar o acesso dessas famílias a seus direitos sociais básicos. Por um lado, as famílias devem assumir e cumprir esses compromissos para continuar recebendo o benefício. Por outro, tais condicionalidades responsabilizam o poder público pela oferta dos serviços públicos de saúde, educação e assistência social. Para que as famílias sejam beneficiadas, estas necessitam estar cadastradas no Sistema Nacional do Cadastro Único versão 7 (online), organizado pelas prefeituras municipais, nas quais o cadastro é analisado e aprovado pelo Ministério do Desenvolvimento Social e Combate a Fome e Miséria (MDS).

A administração e fiscalização do PBF são descentralizadas, ou seja, as prefeituras, o governo estadual, como parceiro do programa, e o Governo Federal são responsáveis pelo Programa. Ademais, não há nenhum tipo de órgão que fiscalize as aplicações feitas pelos beneficiários.

Existem inúmeras controvérsias sobre os efeitos do PBF, sendo que aqueles que defendem o Programa argumentam os efeitos positivos sobre as condições de vida das pessoas marginalizadas e sobre a economia do país como um todo. Em contrapartida, os que criticam, apontam como pontos negativos a geração de um segmento da população "parasitária", que vive do PBF sem trabalhar e, ainda, acusam o governo de usar o Programa como estratégia "populista", visando a manutenção de um segmento político partidário no poder. Entretanto, apesar dessas polêmicas, parece haver um consenso que os efeitos positivos do PBF prevalecem em relação às críticas (DUARTE et al., 2012).

Os trabalhos desenvolvidos por Rocha et al. (2008), Duarte e Silveira Neto (2008), Duarte et al. (2009), Soares et al. (2009), Tavares et al. (2009), Sampaio (2010), Santos et al. (2011) e Baptistella (2012) confirmam as contribuições do programa no melhoramento da frequência escolar; redução da evasão de alunos; aumento do consumo alimentar; e combate à pobreza e à desigualdade em diferentes recortes geográficos brasileiros.

Dentre esses, o presente artigo baseia-se principalmente em estudos realizados por Rocha et al. (2008), Sampaio (2010) e Santos et al. (2011), sendo que a inovação deste artigo em relação ao de Sampaio (2010) consiste em ampliar a área de estudo contemplando todo o município cearense de Mauriti e não se limitando apenas a um estudo de caso em um bairro. Ademais, pretende-se verificar se houve diferenças significativas no consumo de alimentos, uso de materiais escolares e outros componentes de despesas neste município em termos médios decorrente da implementação do PBF. Essa questão não foi investigada em nenhum desses estudos, sendo que o trabalho desenvolvido por Rocha et al. (2008) empregou testes de hipótese para verificar diferenças entre famílias beneficiárias e não beneficiárias pelo PBF.

A avaliação dos efeitos sobre os componentes dos gastos reveste-se de importância, pois possibilita verificar como as famílias beneficiárias alocam os recursos provenientes do PBF. Portanto, em face dessa relevância, o objetivo geral deste estudo consiste em avaliar os efeitos do Programa 
Bolsa Família (PBF) sobre os gastos das famílias beneficiárias no município cearense de Mauriti. Especificamente, propõe-se apresentar as características socioeconômicas das famílias beneficiárias do PBF e verificar se houve ou não diferenças significativas no consumo alimentar e nos diferentes tipos de despesas em termos médios decorrente da implementação do PBF.

\section{PROGRAMA BOLSA FAMÍLIA: ANTECE- DENTES E EFEITOS SOBRE O CONSUMO}

\subsection{Antecedentes do Programa Bolsa Família}

No primeiro semestre de 1995, o Programa Bolsa Escola foi adotado no âmbito municipal, com experiência pioneira no município de Campinas, seguido pelo Distrito Federal e por outros municípios, dando início ao que se denomina hoje de programas de transferência de renda. Entretanto, as várias tentativas de implementação por iniciativa municipal passaram a demonstrar necessidade de federalização do programa, uma vez que a grande maioria dos municípios não possuía capacidade financeira e operacional para garantir o seu funcionamento (ROCHA, 2005 apud RESENDE; OLIVEIRA, 2008).

Segundo esses autores, em 2001 o Governo Federal passou a arcar com as responsabilidades de financiamento, gestão e operacionalização do Programa Bolsa Escola, criando o Fundo de Combate à Pobreza e a Miséria, que passou a financiar programas de transferência de renda associados à educação, ações de saneamento e geradoras de emprego, por serem áreas de maior impacto sobre a pobreza. Com isso, surgiram os programas Bolsa Alimentação do Ministério da Saúde e Bolsa Escola do Ministério da Educação, que davam assistência às mesmas famílias, que passaram a receber um valor que correspondia entre $R \$ 15,00$ a $R \$ 45,00$ por família. As gestantes receberam acompanhamento em caso de desnutrição, assim como as crianças que estavam na escola.

Para retratar a situação socioeconômica dos municípios da população brasileira, em 2001 o Governo Federal instituiu o Cadastro Único, uma ferramenta utilizada na coleta de informações das famílias, conhecendo assim as necessidades sociais para promover formulações e implantações de serviços sociais que os atendam por meio do mapeamento e da identificação das famílias de baixa renda. Esse Cadastro único passou a ser utilizado pelas três esferas do governo, proporcionando maior abrangência dos programas sociais, ajudando a identificar os potenciais beneficiários e evitando a sobreposição de programas para uma mesma família (SAMPAIO, 2010).

Em 2004, por meio de estudos, o governo viu a necessidade de unificação do programa de renda mínima existentes, proporcionando agilidade ao Programa Fome Zero e maior controle dos recursos, propondo desta maneira atender famílias em situação de extrema pobreza e pobreza, com o objetivo de romper o ciclo vicioso da pobreza por meio do investimento em capital humano (SAMPAIO, 2010).

Em 2011, a presidente Dilma Rousseff realizou uma expansão do programa Bolsa Família como parte de seu projeto de governo, o Plano Brasil Sem Miséria (BSM), tendo como foco de atuação os 16 milhões de brasileiros com renda familiar per capita inferior a $R \$ 70,00$ mensais, baseado na garantia de renda, inclusão produtiva e acesso aos serviços públicos (SANTOS et al., 2011).

O Programa Bolsa Família (PBF) possui três eixos principais focados na transferência de renda, nas condicionalidades e nos programas complementares. A transferência de renda promove o alivio imediato da pobreza; as condicionalidades reforçam o acesso aos direitos sociais básicos nas áreas de educação, saúde e assistência social; e as ações e programas complementares objetivam o desenvolvimento das famílias, de modo que os beneficiários consigam superar a situação de vulnerabilidade. 
Esse Programa atende mais de 13 milhões de famílias em todo território nacional de acordo com o perfil e tipos de benefícios: o básico ( $R \$ 70,00)$, pago a famílias consideradas extremamente pobres, cuja renda mensal seja de até $R \$$ 70,00 por pessoa, mesmo que não tenham crianças, adolescentes ou jovens; o variável $(R \$ 32,00)$, pago a famílias pobres, com renda mensal de até $\mathrm{R} \$ 140,00$ por pessoa, desde que tenham crianças e adolescentes de até 15 anos, gestantes e/ ou nutrizes, sendo que cada família pode receber até cinco benefícios variáveis, ou seja, até $\mathrm{R} \$ 160,00$; o variável vinculado ao adolescente (BVJ) $(R \$ 38,00)$, pago a todas as famílias do Programa que tenham adolescentes de 16 e 17 anos frequentando a escola, sendo que cada família pode receber até dois benefícios variáveis vinculados ao adolescente, ou seja, até $R \$ 76,00$; o variável gestante (BVG) $(R \$ 32,00)$, adotado em famílias que possuam em sua composição gestantes, que receberão nove parcelas do beneficio, independente do mês que foi informada a gestação (com limite de até cinco gestantes por família); o variável nutriz (BVN) ( $R \$ 32,00)$ para crianças menores de 6 meses; e o Beneficio para Superação da Primeira Infância (BSP), que contempla famílias beneficiárias com crianças de até 6 anos que permanecem em situação de extrema pobreza mesmo após o recebimento dos benefícios do PBF, podendo receber um novo benefício, que elevará sua renda mensal per capita acima de $\mathrm{R} \$ 70,00$ (MDS, 2013).

Os valores dos benefícios pagos pelo PBF variam de $R \$ 32,00$ a $R \$ 306,00$ conforme a renda mensal da família por pessoa, o número de crianças e adolescentes de até 17 anos e o número de gestantes e nutrizes componentes da família (MDS, 2013).

A tabela 1 mostra o valor do beneficio da família com renda mensal per capita até $R \$ 70,00$, que compreende as famílias caracterizadas em extrema pobreza.

Tabela 1: Valor do benefício da família em situação de extrema pobreza

\begin{tabular}{|c|c|c|c|}
\hline $\begin{array}{l}\text { Número de gestantes, nutrizes, } \\
\text { crianças e adolescentes de até } \\
15 \text { anos }\end{array}$ & $\begin{array}{l}\text { Número de jovens de } 16 \text { a } 17 \\
\text { anos }\end{array}$ & Tipo de benefício & Valor do benefício \\
\hline 0 & 0 & Básico & $\mathrm{R} \$ 70,00$ \\
\hline 1 & 0 & Básico + 1 variável & $\mathrm{R} \$ 102,00$ \\
\hline 2 & 0 & Básico + 2 variáveis & $\mathrm{R} \$ 134,00$ \\
\hline 3 & 0 & Básico + 3 variáveis & $\mathrm{R} \$ 166,00$ \\
\hline 4 & 0 & Básico + 4 variáveis & $\mathrm{R} \$ 198,00$ \\
\hline 5 & 0 & Básico + 5 variáveis & $\mathrm{R} \$ 230,00$ \\
\hline 0 & 1 & Básico + 1 BVJ & $\mathrm{R} \$ 108,00$ \\
\hline 1 & 1 & Básico + 1 variável + 1 BVJ & $\mathrm{R} \$ 140,00$ \\
\hline 2 & 1 & Básico + 1 variável + 2 BVJ & $\mathrm{R} \$ 172,00$ \\
\hline 3 & 1 & Básico + 1 variável + 3 BVJ & $\mathrm{R} \$ 204,00$ \\
\hline 4 & 1 & Básico + 1 variável + 4 BVJ & $\mathrm{R} \$ 236,00$ \\
\hline 5 & 1 & Básico + 3 variáveis + 2 BVJ & $\mathrm{R} \$ 200,00$ \\
\hline 0 & 2 & Básico + 2 BVJ & $\mathrm{R} \$ 146,00$ \\
\hline 1 & 2 & Básico + 1 variável + 2 BVJ & $\mathrm{R} \$ 178,00$ \\
\hline 2 & 2 & Básico + 2 variáveis + 2BVJ & $\mathrm{R} \$ 210,00$ \\
\hline 3 & 2 & Básico + 3 variáveis + 2 BVJ & $\mathrm{R} \$ 242,00$ \\
\hline 4 & 2 & Básico + 4 variáveis + 2 BVJ & $\mathrm{R} \$ 274,00$ \\
\hline 5 & 2 & Básico + 5 variáveis + 2 BVJ & $\mathrm{R} \$ 306,00$ \\
\hline
\end{tabular}

Fonte: Adaptado de MDS, 2013. 
Tabela 2 - Valor do benefício da família em situação de pobreza

\begin{tabular}{|c|c|c|c|}
\hline $\begin{array}{l}\text { Número de gestantes, nutrizes, } \\
\text { crianças e adolescentes de até } \\
15 \text { anos }\end{array}$ & $\begin{array}{c}\text { Número de jovens de } 16 \text { a } 17 \\
\text { anos }\end{array}$ & Tipo de benefício & Valor do benefício \\
\hline 0 & 0 & Não recebe benefício básico & - \\
\hline 1 & 0 & 1 variável & $\mathrm{R} \$ 32,00$ \\
\hline 2 & 0 & 2 variáveis & $\mathrm{R} \$ 64,00$ \\
\hline 3 & 0 & 3 variáveis & $\mathrm{R} \$ 96,00$ \\
\hline 4 & 0 & 4 variáveis & $\mathrm{R} \$ 128,00$ \\
\hline 5 & 0 & 5 variáveis & $R \$ 160,00$ \\
\hline 0 & 1 & $1 \mathrm{BVJ}$ & $\mathrm{R} \$ 38,00$ \\
\hline 1 & 1 & 1 variável + 1 BVJ & $\mathrm{R} \$ 70,00$ \\
\hline 2 & 1 & 2 variáveis + 1 BVJ & $\mathrm{R} \$ 102,00$ \\
\hline 3 & 1 & 3 variáveis +1 BVJ & $\mathrm{R} \$ 134,00$ \\
\hline 4 & 1 & 4 variáveis + 1 BVJ & $\mathrm{R} \$ 166,00$ \\
\hline 5 & 1 & 5 variáveis +1 BVJ & $\mathrm{R} \$ 108,00$ \\
\hline 0 & 2 & $2 \mathrm{BVJ}$ & $R \$ 76,00$ \\
\hline 1 & 2 & 1 variável + 2 BVJ & $\mathrm{R} \$ 108,00$ \\
\hline 2 & 2 & 2 variáveis + 2BVJ & $\mathrm{R} \$ 140,00$ \\
\hline 3 & 2 & 3 variáveis +2 BVJ & $\mathrm{R} \$ 172,00$ \\
\hline 4 & 2 & 4 variáveis +2 BVJ & $\mathrm{R} \$ 204,00$ \\
\hline 5 & 2 & 5 variáveis +2 BVJ & $\mathrm{R} \$ 236,00$ \\
\hline
\end{tabular}

Fonte:Adaptado de MDS, 2013

A Tabela 2 apresenta o valor do beneficio da família com renda mensal per capita de $\mathrm{R} \$ 70,01$ a $R \$ 140,00$, que contempla famílias caracterizadas em situação de pobreza.

\subsection{Efeitos do Programa Bolsa Família sobre o consumo}

Muitos estudos mostram que o programa de transferência de renda Bolsa Família está assumindo um expressivo efeito sobre o consumo das famílias beneficiárias, pois se observa que as famílias que recebem o benefício passam a ter significativo aumento no poder de compra com relação ao período em que não recebiam o benefício.

De acordo com Marques (2005) a teoria econômica de inspiração keynesiana defende que o gasto realizado pelo governo possibilita a aquisição de novas demandas. No caso da transferência de renda para as famílias, o impacto varia conforme a propensão marginal a consumir, sendo que quanto maior for a parcela destinada ao consumo quando a renda for aumentada em uma unidade, maior será o seu efeito. Quanto à transferência do Programa Bolsa Família, principalmente com famílias consideradas como extremamente pobres, a propensão marginal a consumir é das mais elevadas, quando não for igual a um.

O aumento da renda afeta de forma significativa o comportamento de consumo, já que o rendimento mensal consiste em uma das variáveis que mais influenciam o consumo familiar. Dessa forma, com a expansão da renda, as famílias carentes tendem, na maioria das vezes, a destinar os seus recursos para os gêneros alimentícios (RODRIGUES et al., 2008).

Baptistella (2012) também destaca que um dos resultados esperados pela adoção dessa medida de política pública seria o aumento da demanda por alimentos, especialmente da cesta básica, pelas famílias mais vulneráveis da população, ocasionando uma redução dos problemas advindos da insegurança alimentar e, consequentemente, contribuindo para a quebra dos mecanismos de transmissão 
intergeracional da pobreza no país. Entretanto, não há garantias de que o benefício do programa seja efetivamente gasto com alimentos.

Para Resende (2006) apud Tavares (2008), a transferência do PBF para as famílias pobres eleva seu consumo de alimentos, produtos de higiene, educação e vestuário, concluindo que o programa apresenta impactos no bem-estar das famílias, representando um alívio imediato da pobreza. O impacto positivo desse programa sobre o bem-estar das famílias beneficiárias também foi corroborado por Rocha et al. (2008), uma vez que os resultados do modelo estimado indicaram que a propensão marginal de gastos com alimentação, com roupas e com material escolar mostraram-se estatisticamente significantes. Santos et al. (2011) também encontraram influência significativa desse programa nos gastos mensais com alimentação e educação.

Essas famílias beneficiadas com o programa, em grande maioria, são pobres e extremamente pobres, necessitam de uma maior quantidade de alimentos e produtos básicos, aumentando assim o consumo por tais itens para sua subsistência.

A região Nordeste, onde se encontra o município analisado neste estudo, possui uma estrutura de renda relativamente baixa em relação às outras regiões, propiciando maior atenção na demanda de transferência condicionada de renda. De acordo com Freitas Jr. (2010, p. 24):

Pela estrutura de renda da região, mais baixa que no resto do país, o efeito das políticas que mexeram com a renda foi maior aqui. O aumento dessas receitas impulsionou o consumo e atraiu investimentos, especialmente dos grandes grupos de alimentos, bebidas, varejistas e distribuição de alimentos.

Segundo Marques (2005), quanto menos desenvolvido o município for, o que transparece na baixa transferência do ICMS, maior será a importância relativa do Programa Bolsa Família.

\section{METODOLOGIA}

\section{1. Área de estudo, amostragem e fonte dos dados}

Este estudo foi realizado na cidade de Mauriti, localizada na região Sul no estado do Ceará. Segundo o Instituto de Pesquisa e Estratégia Econômica do Ceará (IPECE, 2012), o município compreende uma área absoluta de 1.111,86 km², com distância da capital em linha reta de 406 km. Esta cidade é composta por 44.240 habitantes com base na estimativa de 2010 , sendo que 23.285 residem na zona urbana e 20.955 moram no meio rural. Ademais, este referido município possui um total de 14.544 da população em situação de extrema pobreza.

De acordo com Fonseca e Martins (1996), para calcular o tamanho da amostra para populações finitas por meio da amostragem aleatória simples, utiliza-se a fórmula a seguir:

$$
n=\frac{Z^{2} \cdot p \cdot q \cdot N}{d^{2}(N-1)+Z^{2} \cdot p \cdot q}
$$

onde:

- $\mathrm{n}$ : tamanho da amostra;

- z: abscissa da normal padrão;

- p: estimativa da proporção da característica pesquisada no universo;

- $\mathrm{q}: 1-\mathrm{p}$;

- $\mathrm{N}$ : número total de famílias beneficiárias do Programa Bolsa Família em Mauriti ( $\mathrm{N}=$ 8.496); d: erro amostral.

De acordo com o Relatório de Informações Sociais emitida pela Secretaria de Avaliação e Gestão de Informações (SAGI, 2012), o município de Mauriti possui 8.514 famílias cadastradas que estão enquadradas no perfil de extrema pobreza, 
possuindo renda per capita abaixo de $R \$ 70,00$ (setenta reais). Entretanto, nem todas as famílias cadastradas são beneficiárias. Conforme dados fornecidos pela SAGI (2012), o município possui 8.496 beneficiários do Programa Bolsa Família possuindo renda per capita de até $R \$ 140,00$ (cento e quarenta reais).

Um estudo divulgado pelo IPECE (2013) mostrou que o Ceará tem cerca de 858,3 mil pessoas em situação de extrema pobreza. De acordo com o órgão, em termos proporcionais, o estado apresenta o quarto maior índice do país.

Considerando-se um erro de estimação de $8 \%$ $(d=0,08)$, a abscissa da normal padrão $Z=1,64$, ao nível de confiança de $90 \%$ e $p=q=0,5$ (na hipótese de se admitir o maior tamanho da amostra, já que não se conhecem as proporções estudadas), obteve-se um tamanho da amostra (n) igual a 104 famílias beneficiárias do PBF.

Os dados são de natureza primária, obtida a partir da aplicação de questionários diretamente às famílias beneficiárias e de natureza secundária, extraída de pesquisas realizadas pelo Ministério do Desenvolvimento Social e Combate à Fome (MDS), Instituto de Pesquisa e Estratégia Econômica do Ceará (IPECE), Secretaria de Avaliação e Gestão de Informações (SAGI).

\subsection{Métodos analíticos}

Para atender os objetivos propostos no estudo, foram empregados os métodos de análise tabular e descritiva e o teste t de Student para dados pareados.

Este para dados pareados verifica se as médias de duas populações são ou não significativamente diferentes. O teste é indicado quando se coletam dados de uma mesma pessoa considerando momentos diferentes no tempo, ou seja, para verificar se houve ou não diferenças significativas em termos médios decorrente da implementação de um dado programa.
Neste estudo, as hipóteses a serem testadas são:

- $H_{0}: m_{A}=m_{B^{\prime}}$ não há diferenças significativas entre as médias do consumo de alimentos e dos gastos realizados pelas famílias beneficiárias antes e depois do PBF;

- $\mathrm{H}_{1}: \mathrm{m}_{A} \neq \mathrm{m}_{B}$, há diferenças significativas entre as médias do consumo de alimentos e dos gastos realizados pelas famílias beneficiárias antes e depois do PBF.

Essas hipóteses foram operacionalizadas por meio do SPSS (Statistical Package for the Social Sciences) versão 17.0.

De acordo com Zar (1984) apud Oliveira (2011), para o caso de variâncias populacionais não homogêneas, a estatística t de Student é mensurada pela seguinte equação:

$$
T=\frac{\left(\bar{X}_{A}-\bar{X}_{B}\right)-\left(\mathrm{m}_{A}-\mathrm{m}_{B}\right)}{\sqrt{\frac{S_{A}^{\prime 2}}{n_{A}}+\frac{S_{B}^{\prime 2}}{n_{B}}}}
$$

Em que:

- $\bar{X}_{A}, \bar{X}_{B}$ são as médias amostrais das populações antes e depois da implantação do PBF;

- $\mathrm{m}_{A}, \mathrm{~m}_{B}$ são as médias a serem testadas antes e depois da implantação do PBF;

- $S_{A}^{\prime 2}, S_{B}^{\prime 2}$ são as variâncias amostrais antes e depois da implantação do PBF;

- $n_{A}, n_{B}$ são os números de observações amostrais antes e depois da implantação do PBF. 


\section{RESULTADOS E DISCUSSÃO}

\subsection{Perfil socioeconômico das famílias beneficiárias do Programa Bolsa Família}

Para traçar o perfil socioeconômico das famílias beneficiárias do Programa Bolsa Família, consideram-se as características concernentes à composição familiar, ao gênero e ao nível de escolaridade da pessoa responsável pela família, assim como os tipos de benefícios sociais que essas famílias beneficiárias do PBF recebem. Com base na pesquisa realizada com os beneficiários, verificou-se que, das 104 famílias beneficiárias do PBF, 45 são compostas por três a cinco pessoas, 34 por uma a três pessoas e 25 acima de cinco componentes, indicando que, nos dias atuais, em geral as famílias não pretendem ter mais que três filhos.

Tabela 3 - distribuição absoluta e relativa das famílias beneficiárias quanto à escolaridade da pessoa responsável pela família dos beneficiários do PBF em Mauriti/CE, 2012

\begin{tabular}{l|c|c}
\hline Nível de escolaridade & $\begin{array}{c}\text { Frequência } \\
\text { absoluta }\end{array}$ & $\begin{array}{c}\text { Frequência } \\
\text { relativa (\%) }\end{array}$ \\
\hline Alfabetização & 10 & 9,62 \\
\hline Fundamental incompleto & 53 & 50,96 \\
\hline Fundamental completo & 7 & 6,73 \\
\hline Médio incompleto & 5 & 4,81 \\
\hline Médio completo & 26 & 25,00 \\
\hline Superior incompleto & 3 & 2,88 \\
\hline Total & 104 & 100,00 \\
\hline
\end{tabular}

Fonte: Elaborado com base nos dados da pesquisa.

No tocante ao gênero das pessoas responsáveis pela unidade familiar, os dados da pesquisa de campo mostraram que quase $100 \%$ das famílias beneficiárias do PBF têm como responsável familiar as mulheres, sendo que elas decidem de que forma será gasto o benefício recebido.

Em relação ao nível de escolaridade da pessoa responsável pela família, constatou-se, a partir da Tabela 3, que mais da metade possui apenas o ensino fundamental incompleto, em que muitas das vezes estes só sabem escrever o seu próprio nome. Os dados também indicaram uma parcela de $25 \%$ que possuem o ensino médio completo. Em contrapartida, somente $2,88 \%$ iniciaram uma faculdade.

De acordo com os dados da Tabela 4, 86,54\% das famílias pesquisadas recebem o benefício básico Fome Zero, que é destinado às famílias em extrema pobreza, acrescido do benefício variável Bolsa Escola, repassado às famílias que contenham em sua composição familiar crianças em fase escolar com idade entre 0 e 15 anos. Vale destacar também que 8,65\% recebem somente o benefício básico Fome Zero, pois não possuem na composição familiar crianças ou adolescentes.

Tabela 4 - Distribuição absoluta e relativa das famílias beneficiárias quanto aos tipos de benefícios sociais que as famílias beneficárias do PBF recebem em Mauriti/CE, 2012

\begin{tabular}{l|c|c}
\hline Tipos de benefício & $\begin{array}{c}\text { Frequência } \\
\text { absoluta }\end{array}$ & $\begin{array}{c}\text { Frequência } \\
\text { relativa (\%) }\end{array}$ \\
\hline Fome Zero - BÁSICO & 9 & 8.65 \\
\hline Bolsa Escola & 1 & 0,96 \\
\hline Fome Zero e Bolsa Escola & 90 & 86,54 \\
\hline $\begin{array}{l}\text { Fome Zero, Bolsa Escola e } \\
\text { Bolsa Jovem }\end{array}$ & 2 & 1,92 \\
\hline Fome Zero e Bolsa Jovem & 2 & 1,92 \\
\hline
\end{tabular}

Fonte: Elaborado com base nos dados da pesquisa

\subsection{Comportamento das famílias beneficiárias quanto ao Programa Bolsa Família}

Antes de analisar o comportamento das famílias beneficiárias quanto ao Programa Bolsa Família, é relevante saber o tempo em que a família entrevistada recebe o benefício desse programa. Os dados da pesquisa de campo mostraram que parcela majoritária (86,5\%) dos beneficiários recebe esse benefício a mais de um ano.

Ao se analisar a Tabela 5, percebe-se que houve uma elevação na renda média mensal das famílias que receberam o benefício do PBF. Antes 
do beneficio, a maioria das famílias possuíam uma renda mensal familiar até $1 / 4$ do salário mínimo, sendo que, das 104 famílias entrevistadas, somente três delas recebiam uma renda média mensal acima de $1 / 2$ salário mínimo. Com o recebimento do benefício do PBF, a maior parte das famílias passou a receber entre $1 / 4$ e 1/2 salário mínimo mensal, indicando que mesmo sendo assistido pelo PBF, ainda possuem um nível de renda baixíssimo, em que vivem em situação precária sem ter condições dignas de subsistência. Os dados sinalizam que somente duas famílias beneficiárias auferiram uma renda entre um a dois salários mínimos.

Tabela 5 - Distribuição absoluta e relativa das famílias beneficiárias quanto à renda média familiar mensal antes e depois do Programa Bolsa Família (PBF) na cidade de Mauriti/CE, 2012.

\begin{tabular}{c|c|c|c|c}
\hline \multirow{2}{*}{$\begin{array}{c}\text { Renda familiar (RF) } \\
\text { expressa em SM* }\end{array}$} & \multicolumn{2}{|c|}{ Antes do PBF } & \multicolumn{2}{c}{ Depois do PBF } \\
\cline { 2 - 5 } & $\mathbf{f i} * *$ & $\mathbf{f r}(\%) * *$ & $\mathbf{f i} *$ & $\mathbf{f r}(\%) * *$ \\
\hline $\mathrm{RF} \leq 1 / 4 \mathrm{SM}$ & 72 & 69,24 & 5 & 4,81 \\
\hline $1 / 4 \mathrm{SM}<\mathrm{RF} \leq 1 / 2 \mathrm{SM}$ & 29 & 27,88 & 67 & 64,42 \\
\hline $1 / 2 \mathrm{SM}<\mathrm{RF} \leq 1 \mathrm{SM}$ & 3 & 2,88 & 30 & 28,85 \\
\hline $1 \mathrm{SM}<\mathrm{RF} \leq 2 \mathrm{SM}$ & - & - & 2 & 1,92 \\
\hline Total & 104 & 100,00 & 104 & 100,00 \\
\hline
\end{tabular}

Fonte: Elaborado com base nos dados da pesquisa.

Nota: * SM corresponde ao valor do salário mínimo. Considerouse que um salário mínimo corresponde a $R \$ 622,00$ (valor do salário mínimo vigente em 2012 quando foi realizada a pesquisa de campo). ** fi refere à frequência absoluta e fr à frequência relativa.

Tendo em vista a melhoria da renda média familiar mensal proveniente do Programa Bolsa Família, é importante verificar como as famílias beneficiárias desse programa de transferência de renda estão alocando o recurso. Conforme se verifica pela Tabela 6, o principal destino dos recursos do PBF é a alimentação, uma vez que mais da metade dos entrevistados $(56,73 \%)$ aloca todo seu benefício para o consumo de gêneros alimentícios e que dos 104 beneficiários, 95 utilizam esse recurso para a aquisição de diversos itens, sendo que o grupo de alimentos aparece comum em todas as combinações.

Tabela 6 - Distribuição absoluta e relativa das famílias beneficiárias quanto à alocação do benefício do PBF pelas famílias beneficiárias em Mauriti/CE, 2012

\begin{tabular}{l|c|c}
\hline $\begin{array}{l}\text { Alocação do benefício } \\
\text { do PBF }\end{array}$ & $\begin{array}{c}\text { Frequência } \\
\text { absoluta }\end{array}$ & $\begin{array}{c}\text { Frequência } \\
\text { relativa (\%) }\end{array}$ \\
\hline Alimentação & 59 & 56,73 \\
\hline $\begin{array}{l}\text { Alimentação e material } \\
\text { escolar }\end{array}$ & 26 & 25,00 \\
\hline $\begin{array}{l}\text { Alimentação, material } \\
\text { escolar e moradia }\end{array}$ & 2 & 1,93 \\
\hline $\begin{array}{l}\text { Alimentação e } \\
\text { medicamento }\end{array}$ & 2 & 1,93 \\
\hline Alimentação e moradia & 3 & 2,88 \\
\hline Material escolar & 5 & 4,80 \\
\hline $\begin{array}{l}\text { Material escolar e } \\
\text { medicamento }\end{array}$ & 1 & 0,96 \\
\hline Material escolar e moradia & 1 & 0,96 \\
\hline Moradia & 2 & 1,93 \\
\hline Total & 104 & 100,00 \\
\hline
\end{tabular}

Fonte: Elaborado com base nos dados da pesquisa.

Dada a importância atribuída ao consumo de alimentos pelas famílias beneficiárias do PBF, a Tabela 7 revela que o consumo médio mensal de cada produto alimentício considerado é maior depois do recebimento do benefício do PBF se comparado com a quantidade média consumida antes de receber esse benefício. Todos os gêneros alimentícios avaliados apresentaram acréscimo, sendo que o consumo de iogurte, frutas, verduras, peixes e carnes registraram o maior crescimento, ou seja, o benefício do PBF possibilita uma maior diversificação e quantidade demandada de itens alimentícios. Essa maior tendência de gastos com frutas, verduras e carnes também foi apontada no estudo de Burlandy (2007) apud Rodrigues et al. (2008).

Como se confirma pela Tabela 8, o valor do teste $t$ de Student indica que, em média, a um nível de significância de 1\%, há diferença entre a quantidade consumida de produtos alimentícios pelas famílias beneficiárias antes e depois do PBF, 
Tabela 7 - Consumo médio mensal dos principais gêneros alimentícios das famílias beneficiárias do Programa Bolsa Família (PBF) na cidade de Mauriti/CE, 2012.

\begin{tabular}{l|c|c|c}
\hline Gêneros alimentícios & $\begin{array}{c}\text { Consumo médio mensal } \\
\text { antes do PBF }\end{array}$ & $\begin{array}{c}\text { Consumo médio mensal } \\
\text { depois do PBF }\end{array}$ & Variação percentual \\
\hline Feijão $(\mathrm{kg})$ & 6,83 & 7,72 & 13,03 \\
\hline Arroz $(\mathrm{kg})$ & 15,61 & 16,92 & 8,39 \\
\hline Carnes $(\mathrm{kg})$ & 5,77 & 8,26 & 43,15 \\
\hline Aves $(\mathrm{kg})$ & 2,28 & 3,01 & 32,02 \\
\hline Peixes $(\mathrm{kg})$ & 1,05 & 1,61 & 53,33 \\
\hline Leite $(\mathrm{l})$ & 11,94 & 14,51 & 21,52 \\
\hline logurte $(\mathrm{l})$ & 0,94 & 1,71 & 81,91 \\
\hline Pão e biscoito $(\mathrm{kg})$ & 2,61 & 3,05 & 16,86 \\
\hline Café $(\mathrm{kg})$ & 2,05 & 2,29 & 11,71 \\
\hline Açúcar $(\mathrm{kg})$ & 6,67 & 7,88 & 18,14 \\
\hline Frutas $(\mathrm{kg})$ & 2,54 & 4,10 & 61,42 \\
\hline Verduras $(\mathrm{kg})$ & 2,80 & 4,27 & 52,50 \\
\hline Total & 61,09 & 75,32 & 23,29 \\
\hline
\end{tabular}

Fonte: Elaborado com base nos dados da pesquisa.

Tabela 8 - Resultado do teste t de Student para dados pareados com a comparação entre a quantidade consumida de alimentos "antes" e "depois" do PBF na cidade de Mauriti/CE, 2012

\begin{tabular}{|c|c|c|c|c|c|c|c|c|}
\hline \multirow{3}{*}{$\begin{array}{l}\text { Consumo } \\
\text { médio } \\
\text { mensal de } \\
\text { alimentos }\end{array}$} & \multicolumn{5}{|c|}{ Diferenças Pareadas } & \multirow{3}{*}{$\mathbf{t}$} & \multirow{3}{*}{$\begin{array}{l}\text { Graus de } \\
\text { Liberdade }\end{array}$} & \multirow{3}{*}{$\begin{array}{l}\text { Sig. } \\
\text { (bilateral) }\end{array}$} \\
\hline & \multirow[t]{2}{*}{ Média } & \multirow{2}{*}{$\begin{array}{l}\text { Desvio } \\
\text { padrão }\end{array}$} & \multirow{2}{*}{\begin{tabular}{|c|} 
Erro \\
padrão da \\
média
\end{tabular}} & \multicolumn{2}{|c|}{$\begin{array}{c}\text { Intervalo de Confiança de } \\
95 \% \\
\end{array}$} & & & \\
\hline & & & & Inferior & Superior & & & \\
\hline $\begin{array}{l}\text { Antes e depois } \\
\text { do PBF }\end{array}$ & $-14,23$ & 12,08 & 1,18 & $-16,58$ & $-11,88$ & $-12,01$ & 103 & 0,000 \\
\hline
\end{tabular}

Fonte: Elaborado com base nos dados da pesquisa.

ou seja, o consumo médio mensal de alimentos aumentou após a implantação desse programa de transferência de renda.

\subsection{Efeitos do Programa Bolsa Família sobre os gastos das famílias beneficiárias}

A partir da Tabela 9, verifica-se que os valores de $t$ Student revelam que existe diferença significativa, em nível de significância de $1 \%$ entre os valores médios gastos pelos beneficiários do PBF com alimentação, material escolar, medicamentos, vestuário e aquisição de bens antes e depois da implementação desse programa de transferência de renda. Isso significa que essas famílias despendem mais com esses itens após receberem o benefício do PBF. No tocante à aquisição de bens, os dados da pesquisa de campo mostraram que, dos 104 beneficiários entrevistados, 81, que correspondem a $77,88 \%$ da amostra pesquisada, passaram a comprar produtos duráveis com maior frequência após a inserção no PBF, sendo que os produtos mais demandados foram os utensílios para o lar.

No caso dos gastos com moradia, que contemplam as despesas com aluguel, gás, luz e energia, percebe-se que há uma diferença significativa entre seus valores gastos pelas famílias beneficiárias do PBF em nível de significância de 5\%. Portanto, com base nesses dados, constata-se que o PBF apresenta efeito positivo sobre esses diferentes tipos de gastos. 
Tabela 9 - Resultado do teste t de Student para dados pareados com a comparação entre os gastos das famílias beneficiárias "antes" e "depois" do PBF na cidade de Mauriti/CE, 2012

\begin{tabular}{|c|c|c|c|c|c|c|c|c|}
\hline \multirow{3}{*}{$\begin{array}{l}\text { Gastos dos } \\
\text { beneficiários antes e } \\
\text { depois do PBF }\end{array}$} & \multicolumn{5}{|c|}{ Diferenças Pareadas } & \multirow{3}{*}{$\mathbf{t}$} & \multirow{3}{*}{$\begin{array}{l}\text { Graus de } \\
\text { Liberdade }\end{array}$} & \multirow{3}{*}{$\begin{array}{c}\text { Sig. } \\
\text { (bilateral) }\end{array}$} \\
\hline & \multirow[t]{2}{*}{ Média } & \multirow{2}{*}{$\begin{array}{l}\text { Desvio } \\
\text { padrão }\end{array}$} & \multirow{2}{*}{$\begin{array}{l}\text { Erro } \\
\text { padrão da } \\
\text { média }\end{array}$} & \multicolumn{2}{|c|}{$\begin{array}{c}\text { Intervalo de Confiança } \\
\text { de } 95 \%\end{array}$} & & & \\
\hline & & & & Inferior & Superior & & & \\
\hline Alimentação & $-43,27$ & 43,96 & 4,31 & $-51,82$ & $-34,72$ & $-10,04$ & 103 & 0,000 \\
\hline Material escolar & $-6,03$ & 20,08 & 1,97 & $-9,93$ & $-2,12$ & $-3,06$ & 103 & 0,003 \\
\hline Medicamentos & $-8,38$ & 21,68 & 2,13 & $-12,60$ & $-4,17$ & $-3,94$ & 103 & 0,000 \\
\hline Moradia & $-5,05$ & 21,58 & 2,12 & $-9,24$ & $-0,85$ & $-2,38$ & 10, & 0,019 \\
\hline Vestuário & $-10,80$ & 23,25 & 2,28 & $-15,32$ & $-6,28$ & $-4,73$ & 103 & 0,000 \\
\hline Aquisição de bens & $-7,21$ & 17,65 & 1,73 & $-10,64$ & $-3,78$ & $-4,17$ & 103 & 0,000 \\
\hline
\end{tabular}

Fonte: Elaborado com base nos dados da pesquisa.

\section{CONSIDERAÇÕES FINAIS}

O governo vem buscando alternativas para assegurar o bem-estar social da sociedade, concedendo recursos que façam cumprir o direito constitucional para garantia da alimentação, saúde e educação para todo indivíduo.

O Programa Bolsa Família, em curto prazo, visa reduzir a pobreza, e, em longo prazo, investir em capital humano, quebrando assim o ciclo intergeracional da pobreza. Apesar dos benefícios gerados, alguns estudiosos criticam o Programa Bolsa Família considerando como um programa assistencialista, em que não promove a solução dos problemas de extrema pobreza e pobreza no país. Entretanto, mesmo diante dessas polêmicas, parece haver um consenso de que os efeitos positivos do PBF prevalecem em relação às críticas.

Por meio desse estudo, pode-se concluir que existem diferenças significativas entre os gastos com alimentação, material escolar, medicamentos, moradia, vestuário e aquisição de bens realizados pelos beneficiários antes e depois de passar a receber o benefício do PBF. Portanto, a transferência de renda recebida pelos beneficiários tem um efeito positivo sobre os gastos, visto que as famílias estão destinando o benefício prioritariamente para o alívio ou melhoramento da alimentação, atingindo em curto prazo o alívio imediato da pobreza. Entretanto, em contrapartida, em longo prazo, estas famílias ainda buscam alternativas para deixar a dependência do benefício repassado, necessitando que o governo encontre uma saída para tal situação.

Por fim, é válido destacar que, em posse dos resultados obtidos pela pesquisa de campo quanto à concentração das mulheres como responsáveis pela unidade familiar e a baixa escolaridade da pessoa responsável pela família, percebe-se que a questão é mais complexa do que assistencialismo. No tocante a esse aspecto, sugere-se que, em estudos futuros sobre essa temática, se busque identificar onde estão os homens dessas famílias, se eles moram ou não com as famílias, se trabalham e, caso não trabalhem, se é por opção ou por falta de empregos. 


\section{REFERÉNCIAS}

BAPTISTELLA, J. C. F. Avaliação de Programas Sociais: uma análise do impacto do Bolsa Família sobre o consumo de alimentos. 2012. $101 \mathrm{f}$. Dissertação (Mestrado em Economia Aplicada) Universidade Federal de São Carlos, Sorocaba, SP. 2012.

BRASIL. Ministério do Planejamento, Orçamento e Gestão. Secretaria de Orçamento Federal. Orçamento Federal ao Alcance de Todos: Projeto de Lei Orçamentária Anual - PLOA 2013. Brasília, 2012.

DUARTE, G. A.; ESTEVAN, D. O.; MADEIRA, K. O Programa Bolsa Família e a inclusão social: o estudo do caso do município de Sombrio - SC. In: Encontro de Economia Catarinense, 6, 2012. Anais ... Joinville - SC: APEC, 2012.

DUARTE, G. B.; SAMPAIO, B.; SAMPAIO, Y. Programa Bolsa Família: impacto das transferências sobre os gastos com alimentos em famílias rurais. Revista de Economia e Sociologia Rural. Piracicaba - SP, v. 47, n. 4, p. 903-918, 2009.

DUARTE, G. B.; SILVEIRA NETO, R. M. Avaliando o impacto do Programa Bolsa Família sobre a frequência escolar: o caso da agricultura familiar no Nordeste do Brasil. In: Encontro Regional de Economia, 12, 2008. Anais ... Fortaleza - CE: ANPEC Nordeste, 2008. CDROM.

FONSECA, J. S.; MARTINS, G. A. Curso de Estatística. São Paulo: Atlas, 1996.

FREITAS JR., G. Retirante já era. Carta Capital. 15 de dezembro de 2010, p. 24, com adaptações. Disponível em: <http://www.cartacapital.com.br/ sociedade/retirante-ja-era/>. Acesso em: 22 de maio. 2013.
IPECE. INSTITUTO DE PESQUISA E ESTRATÉGIA ECONÔMICA DO CEARÁ. Perfil Básico Municipal Mauriti - CE. Fortaleza - CE: IPECE. 2012.

IPECE. INSTITUTO DE PESQUISA E ESTRATÉGIA ECONÔMICA DO CEARÁ. IPECE na Mídia - 2013. Disponível em: <http://www.ipece.ce.gov.br/noticias/ ipece-na-midia/cerca-de-134-mil-pessoas-ainda-vivemna-situacao>. Acesso em: 22 de maio. 2013.

MARQUES, M. R. A importância do Bolsa Família nos municípios brasileiros. In: Cadernos de Estudos Desenvolvimento Social em Debate. Brasília: Ministério do Desenvolvimento Social e Combate à Fome, 2005.

MDS. MINISTÉRIO DO DESENVOLVIMENTO SOCIAL E COMBATE A FOME. Bolsa Familia - Benefícios. Disponível em: <http://www.mds.gov.br/bolsafamilia/ beneficios>. Acesso em: 22 de abr. 2013.

MDS. MINISTÉRIO DO DESENVOLVIMENTO SOCIAL E COMBATE A FOME. Relatório de Informações Sociais. Disponível em: <http://aplicacoes.mds.gov.br/sagi/RIv3/ geral/relatorio.php\#>. Acesso em: 22 de maio. 2013.

OLIVEIRA, L. A. S. Políticas públicas e estratégia sustentável de combate à fome: o caso do PAA Leite no município de Quixeramobim Ceará. 2011. 90 f. Dissertação (Mestrado em Economia Rural) Universidade Federal do Ceará, Fortaleza - CE. 2011.

RESENDE, A. C. C.; OlIVEIRA, A. M. H. C. Avaliando resultados de um programa de transferência de renda: o impacto do Bolsa-Escola sobre gastos das famílias brasileiras. Estudos Econômicos, v. 38, n. 2, p. 235-265, 2008.

ROCHA, L. A.; KHAN, A. S.; LIMA, P. V. P. S. Impacto do programa Bolsa Família sobre o bem estar das famílias beneficiadas no estado do Ceará. In: Encontro de 


\section{REFERENCIAS}

Economia do Ceará em Debate, 4, 2008. Anais ... Fortaleza, CE: IPECE, 2008.

RODRIGUES, C. T.; GOMES, A. P.; DIAS, R. S. A expansão do Programa Bolsa Família e as implicações sobre consumo e preços de alimentos: o caso de Viçosa / MG. In: Congresso da Sociedade Brasileira de Economia, Administração e Sociologia Rural, 46, 2008. Anais ... Rio Branco - AC: SOBER, 2008.

SAGI. SECRETARIA DE AVALIAÇÃO E GESTÃO DE INFORMAÇÕES. RI Bolsa Família Cadúnico. Benefícios - 2012. Disponível em: <http:// aplicações.mds.gov.br/sagi/RIv3/geral/relatório. php>. Acesso em: 22 de maio. 2013.

SAMPAIO, M. A. P. O impacto do Programa Bolsa Família sobre o consumo: estudo de caso na cidade de Mauriti-CE. 2010.50 p. Monografia (Graduação em Ciências Econômicas) - Universidade Regional do Cariri, Crato - CE.

SANTOS, D. M. L.; MARTINS, A. P. C.; SOUSA, E. P.; JUSTO, W. R. Impacto do Programa Bolsa Família sobre as condições de vida das famílias beneficiadas em Moreilândia - PE. In: Congresso da Sociedade Brasileira de Economia, Administração e Sociologia Rural Nordeste, 6, 2011. Anais ... Petrolina - PE: SOBER Nordeste, 2011.

SOARES, S.; RIBAS, R. P.; SOARES, F. V. Focalização e cobertura do Programa Bolsa Família: Qual o significado dos 11 milhões de famílias? Texto para Discussão $n^{\circ}$. 1396. Rio de Janeiro: IPEA, 2009.

TAVARES, P. A. Efeito do Programa Bolsa Família sobre a oferta de trabalho das mães. Economia e Sociedade. v. 19, n.3, p. 613-635, 2010.

TAVARES, P. A. Efeito do Programa Bolsa Família sobre a oferta de trabalho das mães. In: Encontro Nacional de Economia da Associação Nacional de Centros de PósGraduação em Economia, 36, 2008. Anais ... Salvador - BA: ANPEC, 2008.

TAVARES, P. A.; PAZELLO, E. T.; FERNANDES, R.; CAMELO, R. S. Uma avaliação do Programa Bolsa Família: focalização e impacto na distribuição de renda e pobreza. Pesquisa e Planejamento Econômico, v. 39, n. 1, 2009. 